Journal of English Teaching Adi Buana, Vol. 03 No. 02, October 2018

\title{
HYBRID LITERACY AND ITS IMPLEMENTATION: CHALLENGES AND OPPORTUNITIES
}

\author{
Irfan Rifai \\ Universitas PGRI Adi Buana Surabaya \\ irfan.rifai@unipasby.ac.id \\ Fajar Susanto \\ Universitas PGRI Adi Buana Surabaya \\ fajarsusanto@unipasby.ac.id
}

\begin{abstract}
This study aims to illustrate the challenges and opportunities of implementing hybrid literacy at Junior High School level in Surabaya. Drawing from amalgamation of interviews with ten teachers who are responsible and concerned with the literacy programme in their schools, classroom observations and documents analysis, the findings indicate that the potential implementation of hybrid literacy within the schools in Surabaya tend to be disrupted by several aspects, all of which are surrounding social and cultural aspect. Social aspect such as students' social condition and school facilities are being the principal challenges in implementing hybrid literacy, whilst cultural aspect such as the school orientation to a particular type of literacy is also prominent to inhibit the implementation of hybrid literacy practices. This study, to some extent, is able to portray the dynamic challenges of hybrid literacy application in the school literacy programmes within the city as well as the potential sources which positively help facilitate the implementation of the future literacy programme, hybrid literacy. Although this study can be used as a reflection of the actor's lens involved in the literacy programme in Surabaya, the data is limited to three schools. The future study, therefore, should anticipate involving more schools and participants (teachers and students) to get richer data findings in regard with the challenges and opportunities of the implementation of the programme.
\end{abstract}

Keywords: Hybrid Literacy, implementation, challenges, opportunity

\section{INTRODUCTION}

The concept of hybrid literacy in this paper is derived from the term 'hybrid' which denotes 'the integration of technology into traditional aspect of literacy instruction' (Taffe and Gwin, 2007) to form a more effective and efficient performance of the students to engage in technological literacy. In regard with the concept of hybrid literacy, the term hybrid is perceived to be the integration of ways in implementing the literacy programme in Indonesia. As it has been indicated that the literacy programme is being one of the targeted programmes implemented by the Government, which is oriented at nurturing the reading skill among the students at all level including Junior and Senior high school (Susanto and Rifai, 2017) 
Hybrid literacy as a school literacy model which is able to give an important contribution in relation to literacy-technology integration as conveyed by Taffe and Gwin (2007), that is, the use of technology in the implementation of school literacy effectively to enhance the learning skills and make up strong reading habits. This quite makes sense since the concept does not putting aside the conventional aspect of literacy practices. Tutty and Alfieri (2008), for example, argue that hybrid literacy is the integration of technology with traditional literacy (traditional paper-pencil and book-based literacy skills) in which the students are quite familiar with these conventional ways such as by using books, papers and pencil. Hybrid literacy, therefore, is perceived to be a means of bridging the students to fully use of technology in the future.

Moreover, the integration of technology in school literacy implementation, according to Fawcett and Snyder (1998) in Taffe and Gwin, (2007), must focus on the capacity that has to continuously develop students' ability to be more productive skills in writing and to integrate information presented in online media becomes "capacity building". In other words, the capacity building, built up from this technology competencies and literacy competencies, has become integral parts required by the students in their personal and professional lives.

However, the school literacy practices conducted at junior high schools in Surabaya tends to be conventional as Susanto and Irfan (2018) reported in their investigation that literacy activities (reading and writing activities) were carried out conventionally and the focus of literacy programme was to improve the students' reading skill and awareness. Taffe and Gwin (2007) assert that the new literacy activities should not collect books or photocopied articles but the students should learn the additional competencies of using internet or search engines, reading web pages, and emerging along with technological advances.

When literacy practices are still around the use of books for reading and writing, these practices can be said as 'the mastery of traditional reading and writing skills (Samir and Korat, 2013). There should be ways to help share the students' work digitally, as by doing this way it can help improve their competencies in a new literacy in their lives. Within this regard, students have awareness in reading and writing as well as possess digital awareness and attitudes, that is, the ability to appropriately use digital tools and facilities (Son et al, 2017).

In addition, the ability to read and write in the $21^{\text {st }}$ century education should be improved through the technology integration in every literacy activities. According to Warschauer (2007) in Chiu (2015), today literacy activities are not only activities of reading and writing on paper or in print paper, but these activities must involve other aspects of text-related interaction such as (a) computer literacy: these activities are related to the ability to use the hardware and software, (b) information literacy: these activities are related to the ability to find, to analyze and criticize information in online media, (c) multimedia literacy: these activities are related to the ability to interpret and to produce documents or texts or other things using various tools integrated between technology and literacy activities, and (d) computer-mediated communication literacy: these activities are related to the ability to comprehend the synchronous and asynchronous computermediated communication. 
What suggested by Warschauer (2007) in Chiu (2015) is that the practices are the expansions of literacy practices and the efforts to follow the very rapid development of education and information are necessarily increased. There should be changes in school literacy practices done in Indonesia after considering what has suggested by Warschauer that literacy practices should integrate to the other aspects of technology (internet and ICT). Therefore, new literacy practices demand that the teachers as the tip of lance in the literacy practices should become proficient at operating technology. The use of multimedia, according to Tan and Guo (2009), (also see, Leu, Kinzer, Coiro, and Cammack, 2004), is necessarily needed in order that the students can "adapt to the rapidly changing information and communication technologies and contexts that continuously emerge in their world and influence all areas of their personal and professional lives"

The use of multimedia in the context of hybrid literacy aims to facilitate the students to have access to various kinds of digital media that can be learnt gradually and integrate the technological competences in new literacy practices. Traditional literacy skills have undergone many kinds of shifts because the development of technology has also influenced the world of education especially for literacy practices in the $21^{\text {st }}$ century. As van Daal and Sandvik (2013) say, "Literacy has undergone transformation from the ability to read and write to the ability to communicate through various means, including technology". The role of multimedia in the integration of technology and literacy is how the students are not only able to use "media" including traditional forms such as books or magazines, but how they are able to apply and function "multimedia" or digital or electronic media.

The importance of technology in literacy practices is asserted by Miller (2011: 453) that "the use of technology is one of leading mandated innovations of the past decade in policy and curriculum and pedagogy". But the problem as Taffe and Gwin (2007) convey according to National Center for Educational Statistic (2000), is the teacher preparation for technology integration is minimal. From this report, it can be perceived that there are teachers found without any well prepared to use computers and internet for instruction. Given the real condition, the literacy practices may meet challenges when hybrid literacy is implemented in the school. Teachers and students must collaborate professionally to engage in the literacytechnology integration. However, teachers take an important role in hybrid literacy because teachers will provide quality literacy technology integration experiences for their students.

How important hybrid literacy is can be showed form a research of literacy in Australia conducted by Eisenclas et al (2016) that has proved that in order to solve the limitedness of literacy materials and the ability of teachers in managing the literacy for school hours, the use of technology is efficiently effective in the language mastery. It is such an important role of technology that literacytechnology integration can give the success of school literacy practices in Indonesia. Therefore, the literacy programme in Indonesia should adopt the use of technology in all literacy activities.

Research on literacy has, in fact, been concerned with how the social, cultural, and educational aspect play significant role on building up better understanding of the effective ways of the programme (Taffe and Gwin, 2007). Whilst many research has focused on seeking the way to search for more 
appropriate literacy programme, little research is emphasized on how the integration of technology which is called hybrid in this sense, is understood from the school' social and cultural context and how these contexts provide information about the challenges and opportunities in implementing hybrid literacy in secondary schools in Surabaya. This study, therefore, aims to explore how social and cultural aspects can be a challenge as well as an opportunity to help realise the hybrid literacy programme within the city.

\section{METHOD}

This study is under the qualitative paradigm in which the methods utilized during data collections are in conjunction with qualitative characteristics. The amalgamation of methods used in the study is centered over individual interviews, classroom observations, and document analysis, all of which are within the qualitative paradigm (Taylor, Bogdan, and DeVault, 2016).

We interviewed ten teachers from three different schools in Surabaya. The teachers are the focal persons in regard with the literacy programme within the city. We interviewed them at different places within the schools. Some of them were interviewed in their office room and some of them were interviewed at the library. We conducted interviews lasted for about forty-five minutes each and recorded in a Sony recorder. Moreover, we also did observation in the classrooms, corridors and in the school library. During our observation in the library, we also collected documents related to literacy practices within the school.

We conducted field research at three state schools within the city. To keep confidentiality of the schools, as research ethic, we anonymized the name of the schools. The schools' profile is illustrated in the following:

1. Junior High School (SMP) A. This state school is one of very reputable (favorite) schools within the city. I term of the social economic condition of the students, the majority of them coming from higher economic class family. The students accepted at the school is selected through the tight competition, mostly the consideration is from the academic achievement.

2. Junior High School B. This school is in southern of the city of Surabaya. The school in term of academic, socio economic background and students' achievement is far much lower if compared to SMP A. Although the students' achievement tends to be lower, they seem enthusiastic to follow the literacy programme.

3. Junior High School C. This state school is located in eastern part of the city. This school tends to be in the middle between SMP A and SMP B. The students' economic background is diverse, but the students' achievement inclines to be homogeneous. Mostly the accepted students are possessing good grades.

\section{Data analysis}

Having recorded, participants' responses were analysed manually, but the process of analysis was conducted quite carefully, careful reading, coding, sorting and coding into topical groups. The data findings then presented in accordance with the research questions. 


\section{FINDINGS AND DISCUSSION}

The findings of the current study are presented in cross case analysis, in that, the findings from school A are compared to the findings of the school B and school $\mathrm{C}$. The idea underlying this intention is that achieving more systematic presentation. The first finding is the challenges of implementing hybrid literacy viewed from the social and followed by considering cultural aspect and the second finding deals with the opportunity to project the application of hybrid literacy.

\section{The Challenges of implementing hybrid literacy}

There are two aspects which are being prominent findings in connection with the challenges of hybrid literacy implementation, social and cultural aspects.

\section{Social aspect}

The data sets indicate that the social condition of the school has significantly informed the ways the school prioritise the form of literacy practices. In this sense, the diverse social condition of the school, the students economic background, the students' achievement, and the school's area shape the way the school select the more appropriate form of literacy for the school. Junior high School A, for example, as its students coming from higher economic family, the literacy practices are directed to the utility of technology or to expose students with technology use on day-to-day life. Junior high school B, on the other hand, perceives that literacy practices which concerned with more moral aspect is more important than that of literacy practices emphasising on nurturing reading and writing skills. The primary reason of focusing on moral building is that moral is the basic education for students and where students do not quite possess intellectual capacity, the focus of literacy practices should also be changed. One of the teachers of SMP B illustrated the condition in the following extract:

What is (literacy) for, if the students don't have good attitudes and behaviour, respect to teachers...moral is more important than just training reading and writing. The social problems in Indonesia are due to moral, people don't have good moral, that they corrupt, kill one another etc...in fact, the students here can't be compared to students at SMP (inner city). (T2)

In conjunction with the SMP B, SMP C tends to have different literacy practices than that of the two schools. This school put on emphasise on building the students skills in reading and writing to achieve better performance on the final examination. The underlying reason of picking up this sort of literacy practices is about the connections between the literacy programme and the school's goals, in that how the literacy practices can support the students' outcome, achieving better scores in the exams. The teacher of SMP C asserts that

I am planning to apply literacy programme next month focusing on the reading speed and understanding...this is because although students read and write every day, their speed reading and understanding is still low. You know (Pak), exams often measure students speed reading and understanding. I believe the programme will be successful, as the students and parents are quite supportive (T6) 
From the extract above, it becomes clear that different literacy practices across schools are due to the school goals and the social condition of the students. The findings of this study corroborate the study conducted by Little (2017) about the social and cultural aspects which play crucial role on building up the children understanding of family literacy practice and as being an inspiration for the family members to implement particular family literacy.

Other than social aspect, the cultural aspect of the school also plays significant role on the selection of the literacy programme.

\section{Cultural aspect}

The findings of the current study show that cultural aspect of the school inclines to prevent the application of the hybrid literacy. The cultural aspect of SMP B, for example, has long been shaped the way the school adopt the school literacy programme, in that when the school tradition is more on religious activities, the literacy practices should be adjusted to the tradition of the school. The school literacy programme, in this sense, should be about reading and getting better understanding of holy books such as Al-Quran and or Bible.

This school has a long history of providing students with moral character... they are get used to reading holy books such as Al-Qur'an and or bible in the school. So, when the Government (Surabaya) asks us to implement literacy programme, we just choose literacy of reading holy books (T8).

The similar phenomenon is also found at SMP A where the school tradition is more on reading, writing and oral communication. The reason of emphasising on three skills is that the school future orientation, equipping students with the latest skills. The school has been aware that the required future skills should be possessed by the students mostly deal with the oral communication in different contexts and across the globe. Therefore, students are expected to have better oral skill through the literacy practice of oral performance. This finding corroborates the previous study which show that acquiring foreign languages is a way to get involved in global interaction (Susanto and Rifai, 2017).The familiarity of technology is also being a primary concern of the school to be introduced to the students that they will be more open living in the global world. Therefore, as our observation and document analysis indicate, the students are quite familiar with the technology use to disseminate information of their literacy practices on online platform such as twitter and blogs.

The significant role of cultural aspect in picking up a particular literacy practices is also apparent at SMP C where the literacy practices are targeted to be a means of accelerating students' academic performance particularly when they have national examination. The basic idea of implementing this kind of literacy practices is about the history of the school. Previously, the school was an 'outskirt' school which quite struggled to improve the quality of its outcome, but when the new system (rayonisasi) implemented by the local government, the school tend to have better inputs. To this end, the literacy practices are now being carried out by focusing on bridging the students' skills and the national examination performance. 
We used to accept students who live near here (the school) and mostly they are from lower economic status. Mostly they didn't perform quite well in academic related activities. But now, we accept more diverse students (T10).

Although, implicitly, the teacher did not say that lower economic status is associated with the lower academic performance, she wants to remind that different culture between lower versus higher economic status is apparent. In addition, without making a judgement, she also wants to assert that the family culture such as reading habits within the family shape the way the students think about the importance of the school literacy programme. This finding is in conjunction with the previous study conducted in the Nordic countries about the significance of cultural aspect on the students' scientific literacy performance (Turmo, 2004). This study is also in similar vein with the literature review study conducted by Van Enk at al., (2008) about the crucial cultural aspect in the implementation of the literacy programme. In this sense, cultural aspect mostly deals with what the students do and what they have not. Without addressing this aspect when implementing the programme, the literacy programme is likely to be meaningless.

Having presented the aspect to which prevents the potential use of hybrid literacy at the secondary school level, the following section illustrating the opportunity of hybrid literacy application.

\section{The Opportunities of Implementing Hybrid Literacy}

Although the three schools differ in the term of the form of literacy practices and the skills being emphasized on their targeted goals of literacy programme, these three schools share similarities in that they are quite open to consider the use of technology on their literacy practices. The school A, for example, as it has been nurtured to technology utility on their literacy practices, the students are quite familiar with hybrid literacy. The similar case of SMP B which has orientation to have skills in reading Al-Quran and other holy books, they are interested in empowering the online applications and the use of technology to enhance their learning and the construction of the moral and character building. In this sense, the school personnel are quite aware of the importance of technology in all aspect of life including in the school literacy programme. When we asked teachers about the future literacy practices, mostly the teachers agree to consider of using technology on their day-to-day literacy practices. The finding of this current study reiterates the previous study which shows the benefits of utilising digital technology in the students' literacy in that it can improve students' score on alphabetical measures (D'Agostinos et al., 2016).

The teachers' awareness about the significance use of technology to accelerate students' performance can be used to indicate that they are quite open with the current issue in education such as the issue of industrial revolution 4.1.

We realise that our era is different from our students'. We need to educate students with what they are familiar with, we need to educate them as the way they live in. So, I agree the use of technology in literacy programme. 
But the problem is that, we sometimes far behind of our students, they are more knowledgeable in technology than us (T5).

In this extract, we can recognise that the teachers have a more positive aspect to integrate their literacy practices into more hybrid.

Although the school personnel are quite open with the concept hybrid literacy, their limitation skills in using and accessing technology in the implementation of hybrid literacy is still probably being an important issue. Intensive trainings and workshops in regard with improving teachers' skills in using technology can be very effective to help reduce the gap between the skills required and the success of the hybrid literacy application.

\section{CONCLUSION}

The findings of the current study illustrate that the two aspects (social and cultural) are the primary factors which contribute to inhibition of the implementation of hybrid literacy at junior high schools in Surabaya. However, despite its two interrelated factors which viewed to hinder the hybrid literacy practices, there also some unrecognized practices which potentially can be explored to mediate the application of hybrid literacy that is the teachers' awareness of the significance role of technology use in literacy practices and the positive attitude of the teachers to consider the integration of technology in literacy in the school activities including school literacy programme. This study is expected to contribute to the variety of literacy practices in Indonesia schools and potentially is expected to fill in the gap about the growing study of literacy in Indonesia and the real practices of literacy programme within Indonesian schools.

\section{REFERENCES}

Chiu, Hazel. (2015). Contemporary Literacy Concepts and Practices of University Students in English Language Education. International Journal of Arts \& Sciences. 8(6): 213-227

D’Agostino, Jerome, D., Rodgers, Emily; Harmey, Sinead; and Brownfield, Katherine. (2016). Journal of Childhood Literacy, 16, 522-548.

Eisenchlas, S, A., Schalley, A. C \& Moyes, G. (2016). Play to learn: self-directed home language literacy acquisition through online games. Internasional Journal of Bilingual Education and Bilingualism, 19 (2): 136-152

Leu, D.J., Jr., Kinzer, C.K., Coiro, J.L., \& Cammack, D.W. (2004). Towards a theory of new literacies emerging from the Internet and other information and communication technologies. In R.B. Ruddell \& N.J. Unrau (Eds.), Theoretical models and processes of reading (5th ed., pp. 1570-1613). Newark, DE: International Reading Association.

Little, Sabine. (2017). A Generational Arc: Early Literacy Practice among Pakistani and Indian Heritage Language Families. International Journal of Early Years Education, 25, 424-438.

Miller, J. (2011). "Teachers' Work in Culturally and Linguistically Diverse Schools." Teachers and Teaching. 17 (4): 451-466 
Shamir, Adina and Korat,Ofra. (2013). Introduction: Technology as a Support for Literacy Achievements for Children at Risk. In A. a. Shamir, Technology as a Support for Literacy Achievements for Children at Risk (Vol. 7, pp. 18). New York: Springer.

Son, Jeong-Bae, Park, Sang-Soon, and Park, Moonyoung. (2017). Digital literacy of language learners in two different contexts. The Jalt Call Journal. 13 (2): 77-96

Susanto, Fajar and Rifai, Irfan. (2017). Narrating Literacy Practices at an Urban Secondary School in Surabaya. Journal of English Teaching Jet Adi Buana, 2 (2), 189-199.

Susanto, Fajar and Rifai, Irfan. . (2018). Teachers' Perception of Literacy Program: Its Implication to their Attitudes and Actions. Journal of English Teaching Adi Buana, 3 (1), 89-100.

Taffe, S. W. (2007). Integrating Literacy and technology: Effective Practice for Grade $K$ 6. New York: The Guilford Press.

Tan, Lynde and Guo, Libo. (2009). From Print to Critical Multimedia Literacy: One Teacher's Foray Into New Literacies Practices. Journal of Adolescent \& Adult Literacy. 53(4): 315-324

Taylor, Steven, J., Bogdan, Robert, and DeVault, Marjorie, L. (2016). Introduction to Qualitative Research Methods: A Guidebook and Resources. $4^{\text {th }}$ Edition. New Jersey: Wiley.

Turmo, Are. (2004). Scientific Literacy and Socio-economic Backgroudn among 15-year-olds---A Nordic Perspectve. Scandinavian Journal of Educational Research, 48, 286-305.

Tutty, J. I. (2008). Teacher Technology Literacy: Effects of Alternative Delivery Modes. I-manager's Journal on School Educational Technology, 4, 50-55.

Van Daal, Victor and Sandvik Jenny Miglis . (2013). The Effects of Multimedia on Early Literacy Development of Children at Risk: A Metaanalysis. In Shamir, Adina and Korat,Ofra. Technology as a Support for Literacy Achievements for Children at Risk. (Vol. 7, pp. 73-119). New York: Springer.

Van Enk, Anneke, Dagenais, Diane, and Toohey, Kelleen. (2008). A Socio-cultural Perspective on School Literacy Research: Some Emerging Considerations. Language and Education, 19, 496-512 